\title{
LEKSIKOGRAFI KAMUS DWIBAHASA PRANCIS-INDONESIA KHUSUS BIDANG BISNIS
}

\author{
Adisti Dwi Utami ${ }^{1} \quad$ Tri Indri Hardini ${ }^{2} \quad$ Yuliarti Mutiarsih ${ }^{3 *}$ \\ ${ }^{1,2,3}$ Pendidikan Bahasa Prancis, Sekolah Pascasarjana, Universitas Pendidikan Indonesia \\ adistidu@gmail.com ${ }^{1)}$, tihardini@upi.edu ${ }^{2}$, tiqique_61@upi.edu ${ }^{3)}$
}

\begin{abstract}
Abstrak
Penelitian ini bertujuan untuk mendeskripsikan leksikografi pada kamus dwibahasa Prancis-Indonesia khusus bidang bisnis yang telah diciptakan dan tersedia pada laman dictionnaire-desaffaires.online. Penelitian ini menerapkan metode deskriptif kualitatif dengan teknik pengumpulan data menggunakan angket dan menggunakan tahapan leksikografi. Angket diisi oleh mahasiswa Departemen Pendidikan Bahasa Prancis Universitas Pendidikan Indonesia yang mengambil mata kuliah Bahasa Prancis Bisnis (Français des Affaires). Hal tersebut bertujuan untuk mengetahui kebutuhan mereka terhadap kamus khusus bidang bisnis. Dari hasil analisis diperoleh informasi bahwa mereka membutuhkan kamus khusus bidang bisnis dalam bahasa Prancis-Indonesia dan menjadikan konten serta struktur informasi sebagai prioritas dalam kamus. Selanjutnya peneliti mendeksripsikan leksikografi dari kamus tersebut, yaitu tahapan penyusunannya dan konten dari kamus berupa makrostruktur dan mikrostruktur kamus. Makrostruktur kamus disusun secara alfabetis, sementara mikrostrukturnya terdiri atas definisi dan informasi gramatikal. Informasi gramatikal yang terdapat pada kamus ini adalah kelas kata, antara lain, kata benda (nomina), kata kerja (verba), kata sifat (adjektiva), dan kata keterangan (adverbia). Dari hasil penelitian dapat disimpulkan bahwa kebutuhan mahasiswa terhadap kamus khusus bidang bisnis dapat dipenuhi dengan penyusunan kamus menggunakan leksikografi.
\end{abstract}

Kata kunci: bahasa Prancis bidang bisnis, kamus, leksikografi

\begin{abstract}
This research aims to describe lexicography in a French-Indonesian bilingual business dictionary that has been created and is available on dictionnaire-desaffaires.online. This research applies a descriptive qualitative method. The data collecting techniques used in this research are questionnaire and lexicographic procedures. The questionnaire is filled by students who learn French Business course (Français des Affaires) at the Departement of French Language, Universitas Pendidikan Indonesia. This research aims to find out the students' needs for business dictionary. The result shows that they need a French-Indonesian business dictionary and they prioritize content and information structure in that dictionary. Moreover, the researcher will describe lexicography in this dictionary, namely the procedures of its preparation and the content of the dictionary including the macrostructure and microstructure. The macrostructure dictionary is arranged alphabetically, while the microstructure one consists of definition and grammatical information. The grammatical information contained in this dictionary consists of four major word classes, namely nouns, verbs, adjectives, and adverbs. It can be concluded that the students' needs for businessspecific dictionary can be fulfilled by compiling a dictionary using lexicography.
\end{abstract}

Keywords: French business, dictionary, lexicography 


\section{PENDAHULUAN}

Kamus merupakan instrumen penting bagi orang-orang yang berkecimpung di bidang bahasa, terutama dalam ranah akademik. Dalam proses pembelajaran bahasa, kamus menjadi media pendukung, baik bagi pendidik maupun peserta didik. Penggunaan kamus tidak hanya sebatas untuk mencari definisi suatu kata, tetapi juga berfungsi untuk memeriksa baku atau tidaknya suatu kata, memeriksa ejaan atau informasi lain, seperti etimologi, kategori kata, bahkan contoh penggunaan kata dalam kalimat.

Penelitian tentang kamus telah banyak dilakukan, di antaranya oleh Rustandi (2016: 188-199) yang mengkaji kamus dwibahasa Arab-Indonesia untuk pembelajar pemula. Hasil penelitiannya memaparkan kesulitan-kesulitan yang dirasakan pengguna kamus sehingga perlu adanya pengembangan kamus pedagogis yang memudahkan pengguna, pelatihan penggunaan kamus, serta kajian kamus lainnya. Wahida (2017: 58-71) meneliti kamus bahasa Arab sebagai sumber belajar dengan melakukan kajian terhadap penggunaan kamus cetak dan kamus digital. Hasilnya dapat disimpulkan bahwa penggunaan kamus bahasa Arab cetak dilakukan dengan cara pencarian secara alfabetis yang berarti harus menguasai ilmu saraf. Sementara itu, penggunaan kamus bahasa Arab digital umumnya dilakukan secara artikulasi sehingga dianggap lebih mudah, efektif, dan efisien.

Penelitian terkait kegiatan perkamusan atau kajian leksikografi juga telah dilakukan oleh Surihaq, Syukri, dan Djafar (2017) yang mengangkat konsep pemerkayaan Kamus Besar Bahasa Indonesia (KBBI) dan politik bahasa dalam dinamika global. Hasil penelitiannya menunujukkan adanya kesenjangan antara aturan bahasa yang ada dan penggunaan bahasa di lapangan. Selain itu, KBBI dianggap sangat berpotensi untuk diperkaya dengan lema baru yang dapat memperkaya bahasa Indonesia. Kemudian, penelitian tentang praktik leksikografi dilakukan pula oleh Supriyanti (2012) yang memfokuskan diri pada nomina persona berorientasi gender dalam KBBI Edisi IV. Penelitian tersebut menghasilkan beberapa temuan, di antaranya, bahwa penyusunan entri kamus dipengaruhi oleh stereotip dalam dua cara, yaitu penyusunan definisi dan penentuan kemunculan beberapa lema dan sublema. Pada penyusunan definisi, stereotip berpengaruh pada penyebutan jenis kelamin atau kata-kata yang dimarkahi gender serta tampak pada penggunaan verba atau adjektiva tertentu dalam definisi yang mencerminkan stereotip yang melekat pada jenis kelamin tertentu. Sementara itu, pada kemunculan lema, tampak lema dan sublema yang mengungkapkan konsep yang merujuk pada perempuan secara lebih terperinci dan lebih banyak dibanding dengan konsep yang merujuk pada laki-laki.

Ditinjau dari leksikon yang dimuat, kamus dapat diklasifikasikan menjadi kamus umum dan kamus khusus. Kosakata dalam kamus khusus didefinisikan lebih detail dan disesuaikan dengan bidang tertentu. Berbeda dengan kamus umum yang lebih mudah ditemukan dan lebih banyak dimiliki, terutama oleh para pelajar bahasa asing, kamus khusus tidak selalu menjadi prioritas. Hal tersebut salah satunya dipengaruhi oleh ketersediaan kamus khusus yang masih terbatas. Fenomena yang terjadi di Departemen Pendidikan Bahasa Prancis, Universitas Pendidikan Indonesia, yaitu mahasiswa tetap menggunakan kamus umum dalam pembelajaran Bahasa Prancis untuk Tujuan Khusus (Français sur Objectifs Spécifiques).

Kamus memiliki karakteristik umum, yaitu tersusun secara alfabetis. Svensen (dalam Setiawan, 2015) mendeskripsikan kamus sebagai dokumen kosakata yang disusun secara alfabetis dan berisi definisi kosakata serta informasi lain yang berkaitan dengan bahasa. 
Di samping karakteristik yang umum dimiliki kamus, kebutuhan pengguna menjadikan kamus terbagi ke dalam beberapa tipe. Tipe kamus menurut Salminen (2015), yaitu 1) kamus bilingual dan kamus monolingual, 2) kamus ekstensif dan kamus intensif, serta 3) kamus ensiklopedia dan kamus kata. Kamus bilingual merupakan kamus yang bahasa sumbernya, yaitu yang digunakan pada kosakata, berbeda dengan bahasa sasaran yang digunakan dalam definisi. Sebaliknya, kamus monolingual hanya menggunakan satu bahasa. Selanjutnya, kamus ekstensif berarti kamus yang mendeskripsikan kosakata global, sedangkan kamus intensif hanya berisi tentang suatu bidang atau ilmu tertentu. Kemudian, yang membedakan kamus ensiklopedia dengan kamus kata adalah kamus ensiklopedia berisi tentang deskripsi suatu benda atau suatu hal yang dilengkapi dengan gambar. Sementara itu, kamus kata mendefinisikan makna kata, etimologi, kelas kata, dan ejaan.

Sebuah kamus memuat beberapa informasi dari setiap lemanya. Lema dalam kamus diseleksi dan disusun berdasarkan kriteria tertentu. Penyusunan dan pengembangan kamus membutuhkan suatu ilmu sebagai landasan. Ilmu yang diterapkan dalam penyusunan kamus adalah leksikografi. Leksikografi didefinisikan sebagai cabang ilmu bahasa mengenai teknik penyusunan kamus (KBBI, 2018). Sejalan dengan definisi tersebut, Salminen (2015: 159) mendeskripsikan leksikografi sebagai berikut, le domaine qui a pour but de mettre en ouvre les techniques pour confectionner des dictionnaires et comme la discipline qui propose une réflexion sur les méthodes qu'exige la confection des dictionnaires. Artinya, leksikografi merupakan bidang yang bertujuan menerapkan teknik-teknik penyusunan kamus dan sebagai disiplin ilmu yang mencerminkan metode-metode yang diperlukan dalam pembuatan kamus.

Sementara itu menurut Martin (2009: 318), la lexicographie est une discipline à michemin entre la philologie, la linguistique et les sciences de la communication, une discipline qui profite aussi des avances de la lexicologie et de l'informatique. Pernyataan tersebut berarti bahwa leksikografi adalah suatu disiplin ilmu di antara filologi, linguistik, dan ilmu komunikasi, yang bermanfaat pula bagi kemajuan leksikologi dan informatika. Selanjutnya, Beccaria (dalam Monteleone, 2003) mengatakan bahwa leksikografi merupakan suatu teknik pembuatan kamus yang didasari oleh ilmu leksikologi, semantik, morfologi, sintaksis, dan metaleksikografi yang meliputi cara membuat kamus dan mempersiapkan lema. Selain itu, leksikografi berarti pula ilmu tentang karakteristik dari setiap jenis kamus dan bahasa yang digunakan dalam kamus tersebut.

Leksikologi sering dianggap sama dengan leksikografi, padahal keduanya merupakan dua hal yang berbeda tetapi saling berkaitan. Leksikologi mengacu pada lema dan maknanya. Hartmann (dalam Setiawan, 2015) berpendapat bahwa leksikologi merupakan ilmu tentang elemen-elemen kosakata suatu bahasa, termasuk di dalamnya makna dan hubungan dengan kata lain serta perubahan bentuk kata dan maknanya berdasarkan waktu. Dengan kata lain, objek leksikologi adalah kosakata.

Terdapat dua istilah terkait kata, yaitu kata fungsional dan kata konten. Kata fungsional adalah kata yang memiliki fungsi gramatikal, misalnya, jadi, kemudian, dan juga yang terdiri atas beberapa kata, seperti itulah sebabnya dan maka dari itu. Kata-kata tersebut digunakan untuk mendukung fungsi gramatikal dan tidak memiliki makna leksikal. Sementara itu, katakata yang memiliki makna leksikal, yaitu kata konten, misalnya, rumah, meja, dan buku.

Kata dalam bahasa Prancis dapat dibedakan menjadi dua, yaitu kata dasar dan kata turunan. Kata dasar adalah unit leksikal yang tidak memiliki imbuhan dan tidak dapat diuraikan menjadi elemen yang lebih kecil. Sementara itu, kata turunan dibentuk sekurang-kurangnya oleh 
dua morfem, yang dapat berupa kata berimbuhan atau kata majemuk. Kata berimbuhan adalah kata-kata yang berubah bentuk dan maknanya karena diberi awalan (afiks), akhiran (sufiks), atau awalan-akhiran (konfiks). Awalan adalah elemen yang ada sebelum kata dasar, sedangkan akhiran adalah elemen yang ditambahkan setelah kata dasar. Secara semantik, awalan dan akhiran memiliki efek yang sama, yaitu membawa perubahan makna terhadap kata dasar. Sebagai contoh, kata transport yang berarti 'transportasi' mendapat akhiran able dalam bahasa Prancis menjadi transportable yang berarti 'dapat diangkut'. Kemudian, kata connaître yang berarti 'mengetahui' berubah maknanya jika diberi awalan mé menjadi méconnaître yang artinya 'mengabaikan'.

Selain kata berimbuhan, kata turunan yang kedua adalah kata majemuk. Kata majemuk dalam bahasa Prancis dapat dibagi dua, yaitu kata majemuk usuels atau umum dan kata majemuk savants atau dalam bahasa Indonesia dikenal dengan kata majemuk neoklasik karena dibentuk oleh kata pinjaman dari bahasa kuno, biasanya Yunani atau Latin. Kridalaksana (dalam Darnis, t.t.) menyebut gejala neoklasik dengan istilah majemuk sintesis karena keduanya merupakan paduan antara bentuk terikat dan bentuk bebas atau antara bentuk terikat dan bentuk terikat. Majemuk itu berasal dari bahasa asing dan sebagian besar merupakan kosakata ilmu pengetahuan. Kata majemuk umum, contohnya, porte-monnaie yang berarti 'dompet'. Dalam hal ini, kata porte sendiri berarti 'pintu' dan monnaie berarti 'mata uang'. Sementara itu, contoh kata majemuk neoklasik adalah écologie.

Dalam praktiknya, leksikografi dapat dibedakan menjadi dua, yaitu leksikografi umum dan leksikografi khusus. Keduanya dibedakan oleh kosakata yang terdapat dalam kamus. Menurut Setiawan (2015) leksikografi umum meliputi teknik penyusunan, perancangan, penggunaan, dan penyuntingan kamus yang berisi kosakata yang digunakan secara umum. Oleh karena itu, data leksikografis ini adalah kosakata umum dan hasilnya adalah kamus umum. Sementara itu, leksikografi khusus adalah teknik penyusunan kamus yang menjelaskan informasi linguistik dari bidang tertentu, seperti hukum, ekonomi, kesehatan, dan lain-lain. Data leksikografi ini berupa kosakata khusus dan karya leksikografinya adalah kamus khusus. Kamus khusus tidak hanya berfokus pada satu bidang, tetapi juga dapat mencakup beberapa bidang. Maka dari itu, dapat disimpulkan bahwa leksikografi dapat menghasilkan kamus umum dan kamus khusus.

Dalam teknik penyusunan kamus terdapat tahap-tahap yang dilakukan oleh leksikograf. Wiegand (dalam Schierholz, 2015: 328) menguraikan lima tahapan dalam proses leksikografi, yaitu (a) the phase of preparation, (b) the acquisition of the material and the data, (c) the treatment of the material and the data, (d) the evaluation of the material and the data, and $(e)$ the preparation of the print process.

Tahap pertama adalah persiapan. Prosesnya meliputi perencanaan periode pembuatan dan konsep kamus. Merencanakan konsep kamus berarti menentukan fungsi kamus, informasi yang akan dimuat dalam kamus, serta desain kamus. Selanjutnya, pada tahap kedua, materi dan data dikumpulkan dari berbagai sumber yang berbentuk lisan atau tulis. Kemudian, materi dan data tersebut dikaji dan diseleksi untuk selanjutnya dievaluasi. Setelah melalui tahapan-tahapan tersebut dan seluruh isi kamus dianggap telah tersusun baik dan benar, tahap terakhir adalah persiapan untuk mencetaknya.

Setiap kamus berisi sekurang-kurangnya daftar kata yang mengandung informasi. Pengaturan daftar kata dalam kamus dikenal dengan istilah makrostruktur. Setiawan (2015: 76) menyatakan bahwa makrostruktur kamus merupakan cara menyusun entri, termasuk subentri, 
dalam sebuah kamus. Lebih lanjut, menurut Martin (2009: 335), La macrostructure doit être composée d'une série d'adresses classées par ordre alphabétique qu'on appelle «entrées». Ces entrées appartiennent au lexique standard de la langue source et un certain nombre de mots techniques de différents domaines spécialisés. Artinya, makrostruktur terdiri atas serangkaian kata dalam urutan alfabetis yang disebut entri. Entri ini memiliki leksikon standar dalam bahasa sumber dan sejumlah kata teknis dari bidang khusus yang berbeda.

Kridalaksana (2009: 149) mendefinisikan makrostruktur sebagai bagian dari kamus yang memuat daftar isi, urutan kelompok lema, petunjuk penggunaan kamus, indeks, dan informasi yang bersifat ekstern, seperti daftar ungkapan asing, pedoman ejaan, dan sebagainya.

Kemudian, seperti yang telah disebutkan di atas bahwa setiap kosakata dalam kamus mengandung sejumlah informasi. Informasi tersebut dikenal dengan mikrostruktur. Menurut Yeka (2016: 6) mikrostruktur mengacu pada informasi yang diberikan pada tiap-tiap lema yang tersusun dalam sebuah kamus. Mikrostruktur merupakan semua informasi yang ditulis setelah lema pokok. Selanjutnya, Kridalaksana (2003: xiii) yang dikutip Supriyanti (2012: 27) menjelaskan mikrostruktur sebagaimana kutipan berikut.

\begin{abstract}
Mikrostruktur kamus bersangkutan dengan susunan informasi dalam entri kamus; mikrostruktur itu mengemas semua informasi berupa format dan perincian entri yang bergantung pada pengguna yang dituju. Bagian inti mikrostruktur memuat lema atau kata kepala dan definisi, sedangkan bagian pelengkap memuat kelas kata, sublema dengan informasinya, contoh, derivasi dan infleksi, lafal, variasi (historis, sosial, dan geografis), gaya bahasa, konteks penggunaan bahasa, sinonim dan antonim, serta etimologi.
\end{abstract}

Informasi dari suatu lema sangat beragam, tetapi tidak seluruhnya selalu ada dalam setiap kamus. Penyusunan informasi tersebut dipengaruhi oleh jenis kamus dan dapat ditentukan oleh leksikograf. Hartmann (2001: 60) dalam Setiawan (2015: 84) membagi informasi lema menjadi dua, yaitu informasi formal dan informasi semantik. Informasi formal lebih berkaitan dengan informasi gramatikal, sedangkan informasi semantik berkaitan dengan informasi makna. Setiap lema dalam setiap entri akan memiliki dua komponen informasi itu. Sejalan dengan penjelasan tersebut, Salminen (2015) membagi pula jenis informasi lema menjadi informasi wajib dan opsional. Informasi yang wajib terdapat dalam kamus adalah kategori gramatikal dan definisi, sedangkan informasi opsional salah satunya adalah etimologi.

Kategori gramatikal menjadi salah satu informasi yang dicari oleh pengguna kamus karena di samping menyajikan makna, lema dalam kamus juga berisi informasi yang berkaitan dengan kategori gramatikalnya. Informasi wajib lainnya adalah definisi. Setiap lema dalam kamus dijelaskan dalam bentuk definisi. Setiawan (2015) menyatakan bahwa definisi memiliki dua fungsi. Fungsi pertama, yaitu sebagai referensi dan fungsi kedua untuk memproduksi teks. Fungsi referensi berkaitan dengan kosakata yang belum diketahui oleh pengguna kamus. Mereka yang mencari definisi sebagai referensi berarti bahwa mereka membutuhkan penjelasan tentang suatu lema. Di sisi lain, pengguna kamus yang ingin memproduksi teks membutuhkan keakuratan kata dengan mencari definisinya.

Selain menentukan makrostruktur dan mikrostruktur kamus, tahap penting lainnya adalah menentukan korpus. Korpus dikumpulkan dan dibatasi sesuai dengan kebutuhan. Menurut Setiawan (2015: 110) pada umumnya korpus leksikografer dibatasi oleh waktu pengumpulan, yang berarti bahwa waktu menjadi pertimbangan utama dalam pengumpulan 
korpus. Hal tersebut menunjukkan bahwa meskipun leksikografer telah terlebih dahulu menentukan jumlah korpus, tetapi proses pengumpulannya tetap dibatasi oleh waktu.

Sehubungan dengan uraian di atas, penelitian ini menghasilkan produk kamus dwibahasa Prancis-Indonesia khusus bidang bisnis. Pembahasan dalam penelitian ini difokuskan pada leksikografi kamus tersebut.

\section{METODE PENELITIAN}

Penelitian ini menggunakan metode deskriptif kualitatif. Bungin (2008: 39) mengungkapkan bahwa rancangan penelitian dalam pendekatan kualitatif bersifat luwes, tidak terlalu rinci, tidak lazim mendefinisikan suatu konsep, serta memberi kemungkinan bagi perubahan-perubahan manakala ditemukan fakta yang lebih mendasar, menarik, dan unik di lapangan. Kemudian, data dalam penelitian ini disajikan secara deskriptif. Hal ini sesuai dengan karakteristik penelitian kualitatif yang diuraikan oleh Yusuf (2014: 333), yaitu bentuk data yang dikumpulkan berupa gambar, kata-kata, dan tidak dalam bentuk angka. Lalu, data disajikan dalam bentuk deskriptif atau naratif dan bersumber dari data yang dikumpulkan.

Langkah awal dalam penelitian ini adalah menganalisis kebutuhan mahasiswa Departemen Pendidikan Bahasa Prancis UPI yang mengontrak mata kuliah Bahasa Prancis Bisnis (Français des Affaires). Hal tersebut bertujuan agar kamus yang disusun dapat memenuhi kebutuhan mereka dalam pembelajaran. Untuk mendapatkan data tersebut, peneliti menggunakan angket yang diisi oleh 27 orang mahasiswa. Pertanyaan angket dikembangkan dari kisi-kisi sebagai berikut.

Tabel 1

Kisi-Kisi Angket Analisis Kebutuhan Mahasiswa terhadap Kamus Dwibahasa Prancis-Indonesia Khusus Bidang Bisnis

\begin{tabular}{clcc}
\hline No. & \multicolumn{1}{c}{ Aspek yang Ditanyakan } & $\begin{array}{c}\text { Jumlah } \\
\text { Pertanyaan }\end{array}$ & $\begin{array}{c}\text { Nomor } \\
\text { Pertanyaan }\end{array}$ \\
\hline 1 & $\begin{array}{l}\text { Minat mahasiswa terhadap mata kuliah } \\
\text { keahlian Prancis untuk Tujuan Khusus } \\
\text { (Français sur Objectifs Spécifiques) }\end{array}$ & 2 & 1,2 \\
\hline 2 & $\begin{array}{l}\text { Persiapan mahasiswa menghadapi mata } \\
\text { kuliah Bahasa Prancis Bisnis (Français des } \\
\text { Affaires) }\end{array}$ & 3 & $3,4,5$ \\
\hline 3 & $\begin{array}{l}\text { Penggunaan kamus dalam pembelajaran } \\
\text { bahasa Prancis }\end{array}$ & 1 & 6 \\
\hline 4 & Penggunaan kamus khusus bidang bisnis & 1 & 7 \\
\hline 5 & $\begin{array}{l}\text { Penggunaan kamus digital khusus bidang } \\
\text { bisnis }\end{array}$ & 5 & $8,9,10,11,12$ \\
\hline 6 & $\begin{array}{l}\text { Jenis kamus khusus bidang bisnis pilihan } \\
\text { mahasiswa }\end{array}$ & 2 & 13,14 \\
\hline
\end{tabular}

Data yang selanjutnya dikumpulkan berupa kata-kata yang akan dijadikan entri kamus khusus. Data tersebut diperoleh dari berbagai sumber tertulis, yaitu kamus cetak, kamus-kamus daring, dan buku ajar bidang bisnis untuk kemudian diseleksi sesuai dengan kebutuhan, yaitu hanya kosakata yang berkaitan dengan bidang bisnis. Selain kosakata bidang bisnis, data lain yang terdapat dalam kamus ini adalah contoh kalimat dan gambar sebagai pelengkap. Dengan demikian, data tambahan tersebut juga diseleksi agar sesuai dengan fungsinya. Kemudian, 
sesuai dengan tahapan leksikografi, langkah berikutnya adalah pengolahan data. Artinya, katakata yang terkumpul diurutkan secara alfabetis dan dilengkapi dengan informasi atau mikrostruktur kamus. Proses pengolahan data disertai pula dengan evaluasi sebelum akhirnya dianggap siap untuk diterbitkan.

\section{PEMBAHASAN}

Hasil penelitian ini berupa paparan tentang proses penyusunan serta isi kamus dwibahasa Prancis-Indonesia khusus bidang bisnis. Penyusunan kamus ini didasari oleh kebutuhan mahasiswa Departemen Pendidikan Bahasa Prancis UPI yang mengambil mata kuliah Bahasa Prancis Bisnis (Français des Affaires). Hasil angket menunjukkan bahwa seluruh mahasiswa menggunakan kamus dalam kegiatan pembelajaran bahasa Prancis dan 55,6\% di antaranya menggunakan kamus dwibahasa Prancis-Indonesia. Namun, mereka tidak memiliki kamus khusus bidang bisnis untuk menunjang pembelajaran Français des Affaires. Mayoritas mahasiswa $(59,3 \%)$ hanya mengumpulkan informasi sebagai persiapan dalam menghadapi mata kuliah tersebut. Terkait dengan kebutuhan terhadap kamus khusus bidang bisnis, 96,3\% mahasiswa Français sur Objectifs Spécifiques memilih kamus khusus bidang bisnis dwibahasa, yaitu dalam bahasa Prancis-Indonesia. Selanjutnya, 77,8\% di antaranya memilih kamus versi daring.

Kamus dwibahasa Prancis-Indonesia khusus bidang bisnis disusun dengan mengacu pada kriteria penyusunan kamus digital dari Ball dan Bothma (2018). Terdapat tujuh kriteria untuk dievaluasi, yaitu konten, struktur informasi, navigasi, akses, menu bantuan, personalisasi, dan menu komentar. Hasil angket menunjukkan bahwa mahasiswa yang mengambil mata kuliah Français des Affaires menekankan konten dan struktur informasi sebagai prioritas dalam kamus.

\section{Leksikografi Kamus Dwibahasa Prancis-Indonesia Khusus Bidang Bisnis}

Penyusunan kamus dwibahasa Prancis-Indonesia khusus bidang bisnis dimulai dengan pengumpulan kata-kata dan istilah yang berhubungan dengan bidang bisnis. Kata-kata tersebut dikumpulkan dari berbagai sumber, baik cetak maupun elektronik. Kamus dwibahasa PrancisIndonesia khusus bidang bisnis dibuat dalam versi daring dan dapat diakses di laman dictionnaire-desaffaires.online. Kamus tersebut menyediakan 2.050 entri. Makrostrukturnya disusun secara alfabetis.

Mikrostruktur yang tersedia dalam kamus tersebut adalah definisi dan informasi gramatikal. Ditinjau dari segi bahasa, sehubungan dengan tipe kamus, yaitu bilingual (dwibahasa) dengan menggunakan bahasa Prancis-Indonesia, definisi setiap lema disajikan dalam bahasa Indonesia. Kemudian, ditinjau dari cakupan leksikon yang dimuat dalam kamus, tipe kamus ini adalah kamus khusus bidang bisnis. Maka dari itu, pendefinisian kata dilakukan berdasarkan ilmu bisnis.

Informasi gramatikal yang terdapat dalam kamus berupa kelas kata, yaitu kata benda (nomina), kata kerja (verba), kata sifat (adjektiva), dan kata keterangan (adverbia). Informasi gramatikal dicantumkan tepat setelah lema. Dalam bahasa Prancis, terdapat dua jenis kata benda yang dibedakan berdasarkan jenis kelamin, yaitu kata benda maskulin dan feminin. Kata benda maskulin ditandai dengan (n.m.) yang berarti nom masculin, sedangkan kata benda feminin 
ditandai dengan (n.f.) yang berarti nom feminin, misalnya, chômage (n..m.) yang berarti 'pengangguran' atau 'keadaan menganggur' dan compagnie (n.f.) yang berarti 'perusahaan'.

\section{Gambar 1}

Makrostruktur Kamus Secara Alfabetis

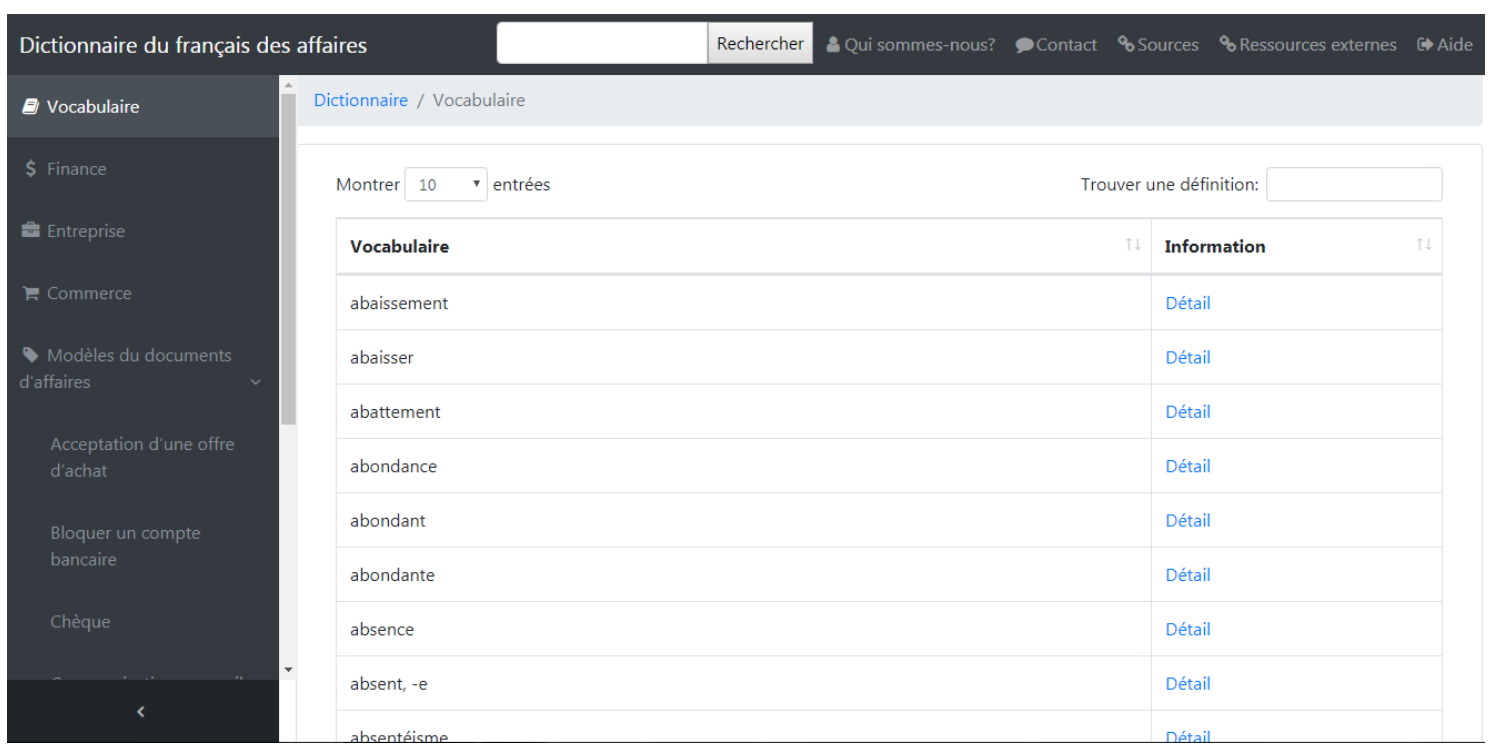

Kata kerja yang terdapat dalam kamus meliputi kata kerja transitif, kata kerja intransitif, gabungan keduanya, dan dilengkapi pula dengan kata kerja pronomina. Kata kerja transitif merupakan kata kerja yang memerlukan objek untuk menjadi penjelas. Kata kerja transitif dalam bahasa Prancis, seperti yang dikatakan Tobing (2012: 47-59), bisa diikuti oleh objek langsung, objek tidak langsung, dan gabungan keduanya. Kata kerja transitif yang diikuti oleh objek langsung atau objek tidak langsung atau disebut verba ekatransitif. Kata kerja transitif yang diikuti oleh dua objek, langsung dan tidak langsung atau disebut verba dwitransitif. Kata kerja transitif diikuti objek langsung ditandai dengan (v.tr.dir.) yang berarti verbe transitif direct. Contohnya:

\section{Gambar 2}

Kata kerja transitif dengan objek langsung

\section{commander (v.tr.dir.)}

\section{Définition}

memesan 
Kata kerja commander memerlukan objek langsung yang berfungsi sebagai penjelas. Misalnya, Il commande une machine artinya 'Ia memesan sebuah mesin'. Une machine merupakan objek yang langsung diletakkan setelah kata kerja.

Sementara itu, kata kerja transitif yang diikuti objek tidak langsung diinformasikan dengan (v.tr.indir.) yang berarti verbe transitif indirect. Kata kerja jenis ini membutuhkan objek tidak langsung, yaitu disertai dengan preposisi. Gambar 3 berikut ini adalah contoh kata kerja transitif dengan objek tidak langsung.

Gambar 3

Kata kerja transitif dengan objek tidak langsung

\section{adhérer (v.tr.indir.)}

\section{Définition}

menjadi anggota

Kata kerja jenis ini membutuhkan objek tidak langsung, yaitu disertai dengan preposisi. Contohnya: Je decide d'adhérer à l'assurance-chômage yang berarti 'Saya memutuskan untuk menjadi anggota asuransi pengangguran'. Di antara kata kerja 'adhérer' dan objek 'assurancechômage' harus dibubuhkan preposisi à.

Selanjutnya, kata kerja yang terdapat pada kamus ini adalah kata kerja intransitif yang tidak memerlukan objek sebagai penjelas.

Gambar 4

Kata kerja intransitif

\section{prospérer (v.intr.) \\ Définition}

sukses; tumbuh

Gambar 4 menunjukkan salah satu lema dalam kamus yang memiliki kelas kata sebagai kata kerja intransitif dengan tanda (v.intr.) yang berarti verbe intransitif. Kata tersebut dapat digunakan, misalnya, dalam kalimat Les deux entreprises prospèrent ensemble yang artinya 
'Kedua perusahaan itu tumbuh bersama'. Kata kerja prospérer berfungsi sebagai predikat tanpa memerlukan objek.

Kata kerja berikutnya, yaitu gabungan antara transitif dan intransitif. Verba jenis ini dapat diikuti oleh objek atau tanpa objek. Gambar 5 di bawah ini adalah salah satu contoh yang terdapat pada kamus. Économiser sebagai kata kerja transitif, misalnya, digunakan dalam kalimat Elle économise son argent pour voyager yang artinya 'Ia menabung uangnya untuk berlibur'. Predikat 'menabung' dalam kalimat tersebut diikuti oleh objek uangnya sebagai penjelas. Sebagai kata kerja intransitif, kalimatnya dapat berbunyi sebagai berikut: Elle économise plus pour acheter une voiture yang berarti 'Ia menabung lebih banyak untuk membeli sebuah mobil'. Dalam kalimat tersebut tidak terdapat objek setelah predikat menabung.

Gambar 5

Kata kerja gabungan transitif dan intransitif

\section{économiser (v.tr.dir., v.intr.)}

\section{Définition}

menabung; mengurangi pengeluaran;

menyisihkan sebagian dari pendapatan untuk investasi

Jenis kata kerja terakhir yang terdapat dalam kamus adalah pronomina. Menurut Ardiyanti, Usman, dan Bandu (2018: 182) pronomina merupakan kata yang menggantikan kata benda atau frasa nominal. Dalam penggunaannya pada kalimat, pronomina selalu disesuaikan dengan kuantitas, subjek, dan jenis kata. Dalam KBBI daring (2018), pronomina didefinisikan sebagai kata yang dipakai untuk mengganti orang atau benda. Dalam kaidah bahasa Prancis, pronomina dapat bermakna pasif, reflektif, atau menunjukkan suatu keadaan timbal balik (saling).

Pronomina dalam kamus ditandai dengan (v.pron.) yang berarti verbe pronominal. Salah satu contoh pronomina yang terdapat dalam kamus dwibahasa Prancis-Indonesia khusus bidang bisnis dapat dilihat pada Gambar 6 berikut ini. 


\section{Gambar 6}

Kata kerja pronominal

\section{rétrécir (v.pron.)}

Définition

\section{menyusut}

Kata kerja rétrécir tersebut dapat diterapkan contohnya pada kalimat Les prix continuent d'augmenter de sorte que le pouvoir d'achat se rétrécit yang artinya 'Harga terus naik sehingga daya beli menyusut'. Dalam hal ini, pronomina tersebut memiliki fungsi reflektif.

Selanjutnya, lema dalam kamus dwibahasa Prancis-Indonesia khusus bidang bisnis memiliki kelas kata adjektiva yang ditandai dengan (adj.). Adjektiva atau kata sifat ditempatkan setelah kata benda dan berfungsi menerangkan kata benda tersebut. Dalam bahasa Prancis, terdapat adjektiva feminin dan adjektiva maskulin serta ada pula adjektiva yang dapat berlaku, baik untuk nomina feminin maupun maskulin.

\section{Gambar 7}

Adjektiva feminin dan adjektiva maskulin

\section{innovant, -ante (adj.)}

\section{Définition}

inovatif

Adjektiva seperti pada Gambar 7 berbeda untuk nomina feminin dan maskulin. Lema seperti itu dibuat menjadi satu entri untuk memudahkan pengguna kamus. Adjektiva jenis ini biasanya mengalami penambahan untuk jenis kelamin feminin, seperti dalam contoh yaitu innovant untuk menjelaskan nomina maskulin dan innovante untuk menjelaskan nomina feminin.

Selanjutnya contoh adjektiva yang berlaku untuk menjelaskan nomina feminin dan maskulin sekaligus adalah seperti pada Gambar 8 berikut. 
Gambar 8

Adjektiva untuk nomina feminin dan maskulin

\section{consomptible (adj)}

\section{Définition}

\section{dapat digunakan; dapat dimakan}

Kelas kata terakhir yang menjadi informasi gramatikal dalam kamus ini adalah adverbia. Adverbia atau dikenal pula dengan kata keterangan berfungi untuk menjelaskan verba atau kata kerja, contohnya gratuitement yang berarti 'secara gratis'.

Selanjutnya, ditinjau dari bentuknya, kata dalam kamus ini terdiri atas kata dasar, kata berimbuhan awalan, kata berimbuhan akhiran, dan kata berimbuhan awalan-akhiran.

Gambar 9

Kata dasar

\section{bancaire (adj.)}

Définition

yang berhubungan dengan perbankan

Gambar 10

Kata berimbuhan awalan

\section{interbancaire (adj.)}

\section{Définition}

yang berkaitan dengan hubungan antar bank

Pada Gambar 10, kata dasar bancaire mendapat awalan inter- menjadi interbancaire sehingga mengalami perubahan makna. 
Selanjutnya pada Gambar 11, adjektiva annuel yang berarti 'tahunan' mendapat akhiran -ment sehingga mengalami penyesuaian menjadi annuellement. Akhiran tersebut selain mengubah makna, juga mengubah kelas katanya menjadi adverbia.

Gambar 11

Kata berimbuhan akhiran

\title{
annuellement (adv.)
}

Définition

setiap tahun

Jenis kata terakhir adalah kata yang mendapat awalan sekaligus akhiran. Contoh kata tersebut dapat dilihat pada Gambar 12 berikut ini.

Gambar 12

Kata berimbuhan awalan-akhiran

\section{intransportable (adj.)}

\section{Définition}

yang tidak dapat dipindahkan

Kemudian, Gambar 13 di bawah ini menunjukkan kata majemuk umum yang terbentuk dari dua kata dasar maison yang berarti 'rumah' dan mère yang berarti 'ibu'. Kedua kata tersebut memiliki makna baru saat digabungkan, yaitu 'perusahaan induk'.

Gambar 13

Kata majemuk umum

\section{maison-mère (n.f.)}

\author{
Définition
}

perusahaan induk 
Data lain yang melengkapi kamus ini adalah gambar-gambar agar mahasiswa dapat memvisualisasikan kata yang dicari. Gambar 14 berikut ini adalah salah satu contohnya.

\section{Gambar 14}

Gambar sebagai informasi tambahan pada lema

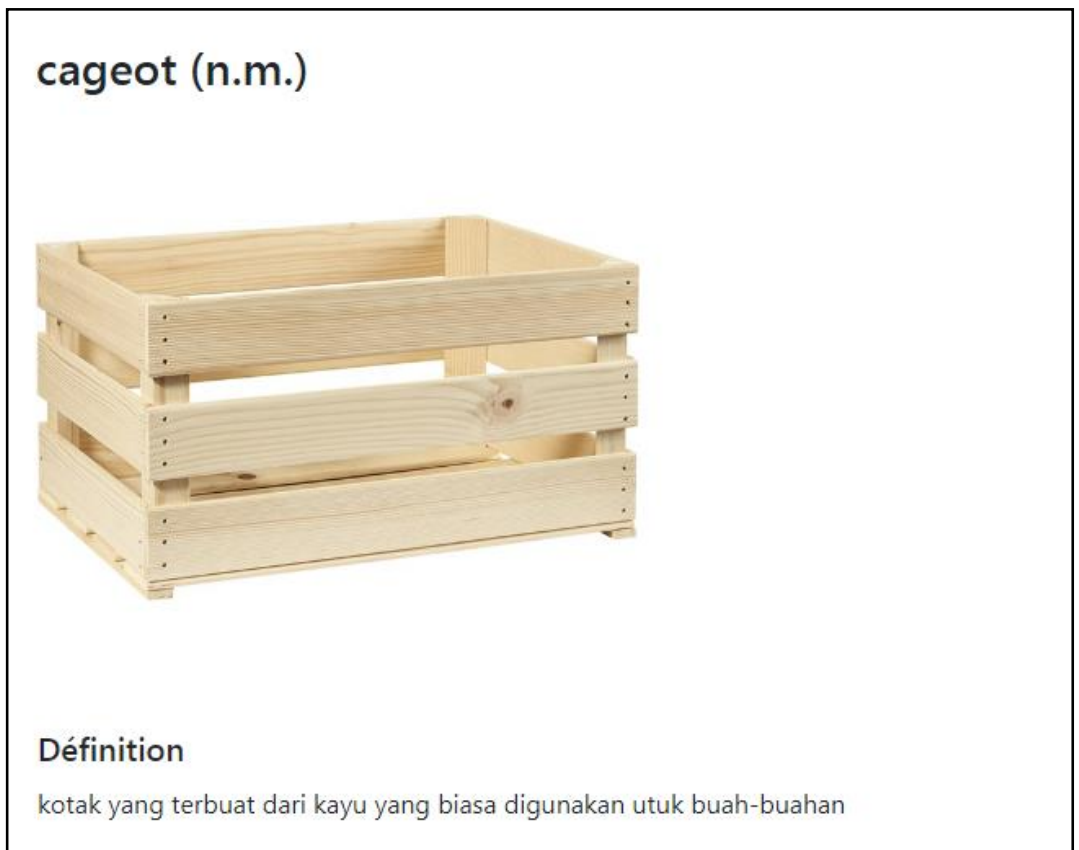

Selain itu, ada pula contoh penggunaan kata dalam kalimat agar definisi lema dapat lebih dipahami sesuai dengan bidangnya. Gambar dan contoh kalimat hanya terdapat pada sebagian lema. Contoh penggunaan lema dalam kalimat dapat ditemukan pada kamus seperti pada Gambar 15 berikut ini.

\section{Gambar 15}

\section{Contoh penggunaan lema dalam kalimat}

\section{passif (n.m.)}

\section{Définition}

total ekuitas, modal pinjaman, dan utang

\section{Exemple}

L'allégement du passif par l'obtention de délais de paiement nous sauve provisoirement de la faillite.

(http://www.projetdafa.net/article.php? id $=1 \&$ numindex $=2268 \&$ vocable $=$ oui $\&$ cat $=($ n\&aide $=$ defs $)$ 
Tambahan lain di luar entri kamus adalah contoh-contoh dokumen profesional dalam bahasa Prancis sebagai referensi bagi mahasiswa. Dokumen tersebut meliputi surat penerimaan tawaran penjualan (acceptation d'une offre d'achat), surat pemblokiran akun bank (bloquer un compte bancaire), contoh sebuah cek (chèque), contoh komunikasi melalui surel (communication par mail), surat cuti melahirkan (congé de naissance), contoh daftar riwayat hidup $(\mathrm{CV})$, surat permohonan pekerjaan (demande d'amploi), surat motivasi (lettre de motivation), contoh invois (modèle de facture), dan surat penangguhan kontrak asuransi (suspension d'un contrat d'assurance).

Seluruh informasi yang terdapat pada kamus dwibahasa Prancis-Indonesia khusus bidang bisnis disusun sesuai konteks agar kebermanfaatannya dapat dirasakan pengguna.

\section{SIMPULAN}

Penelitian ini menunjukkan masih jarangnya penggunaan kamus khusus di lingkungan akademik, sebagai contoh fenomena yang terjadi, yaitu kamus khusus bidang bisnis untuk mata kuliah Français des Affaires. Mahasiswa yang mengontrak mata kuliah tersebut tidak memiliki atau mempersiapkan kamus khusus bidang bisnis. Padahal, sesungguhnya mahasiswa membutuhkan kamus khusus untuk menunjang pembelajaran. Hal tersebut dibuktikan dengan hasil angket yang menunjukkan bahwa mereka memilih kamus khusus bidang bisnis dalam bahasa Prancis-Indonesia untuk digunakan dalam perkuliahan. Sesuai dengan tujuan dalam penelitian ini, dapat disimpulkan bahwa penyusunan suatu kamus membutuhkan ilmu leksikografi. Proses penyusunannya disesuaikan dengan jenis kamus yang akan dibuat. Secara umum, penyusunan kamus dwibahasa Prancis-Indonesia khusus bidang bisnis ini menggunakan tahapan leksikografi yang dikemukakan oleh Wiegand (dalam Schierholz, 2015: 328). Tahapan tersebut, antara lain, perencanaan, pemerolehan data, pengolahan data, evaluasi data, dan persiapan pencetakan yang dalam penelitian ini semua tahapan tersebut berarti memublikasikan secara daring. Tipe kamus, yaitu kamus khusus dwibahasa memengaruhi proses penyusunan dalam hal pendefinisian. Definisi menjadi salah satu bagian mikrostruktur kamus ini, di samping informasi gramatikal. Definisi setiap lema disesuaikan dengan konteks bisnis dan disajikan dalam bahasa Indonesia. Kemudian, informasi gramatikal yang terdapat dalam kamus ini, yaitu kelas kata: kata kerja, kata benda, kata sifat, dan kata keterangan. Mikrostruktur ditempatkan setelah lema, sedangkan makrostrukturnya disusun secara alfabetis.

Kamus khusus bermanfaat untuk memahami kata dan menggunakannya sesuai dengan konteksnya. Penelitian ini diharapkan dapat berguna bagi para peneliti di bidang yang sama untuk menyusun kamus-kamus lain dengan menggunakan leksikografi.

\section{CATATAN}

*Penulis berterima kasih kepada mitra bestari yang telah memberikan saran-saran dan masukan yang sangat berarti untuk perbaikan tulisan ini.

\section{DAFTAR PUSTAKA}

Ardiyanti, A., Usman, M., \& Bandu, I. (2018). Pembelajaran Kosakata Bahasa Prancis dengan Media Flashcard (Studi Kasus pada Mahasiswa Sastra Prancis). Jurnal Ilmu Budaya, Vol. 6 (1): 176 - 186. http://journal.unhas.ac.id/index.php/jib/article/view/4327. Diunduh pada 11 November 2018. 
Ball, L.H., et Bothma, T.J.D. (2018). Establishing Evaluation Criteria for E-Dictionaries. Library Hi Tech, Vol. 36 Issue: 1, pp.152-166, https://doi.org/10.1108/LHT-02-20170031.

Bungin, B. (2008). Analisis Data Penelitian Kualitatif. Jakarta: Rajawali Pers.

Darnis, A.D. (t.t.). Majemuk, Idiom, dan Frasa: Konsep dan Perbedaannya. Diakses dari http://badanbahasa.kemdikbud.go.id/lamanbahasa/content/majemuk-idiom-dan-frasakonsep-dan-perbedaannya.

Kridalaksana, H. (2009). Kamus Linguistik (Edisi Keempat). Jakarta: Gramedia.

Martin, N. C. (2009). Lexicographie et Traduction (2): Macrostructure et Microstructure des Dictionnaires: Les Entrées, Les Articles et Les Définitions Lexicographiques. Entreculturas (1): $351 \quad$ - 364. http://entreculturasuma.comimagine.es/wpcontent/uploads/2017/04/Entreculturasn.\%C3\%9F1.COMPLETO.2009.pdf. Diunduh pada 9 November 2018.

Monteleone, M. (2003). Lexicographie et Dictionnaires Électroniques. Des Usages Linguistiques aux Bases de Données Lexicales. Autre [cs.OH]. Université Paris.

Rustandi, E. (2016). "Kamus Dwibahasa Arab-Indonesia untuk Pembelajar Pemula". Edusentris, Jurnal Ilmu Pendidikan dan Pengajaran, Vol. 3 (2): 188-199. http://ejournal.sps.upi.edu/index.php/edusentris. Diunduh pada 7 November 2018.

Salminen. (2015). La Lexicologie. Paris: Armand Colin.

Schierholz, S. J. (2015). Methods in Lexicography and Dictionary Research. Lexikos 25: 323352. http://dx.doi.org/10.5788/25-1-1302.

Setiawan, T. (2015). Leksikografi. Yogyakarta: Penerbit Ombak.

Supriyanti, N. (2012). Praktik Leksikografi atas Nomina Persona Berorientasi Gender dalam Kamus Besar Bahasa Indonesia Edisi IV. Tesis pada Universitas Indonesia.

Syukri, M., Sirulhaq, A., \& Djafar, S. (2017). Konsep Pemerkayaan Kamus Besar Bahasa Indonesia dan Politik Bahasa dalam Dinamika Global. FKIP E-PROCEEDING, 1-10. Diakses dari https://jurnal.unej.ac.id/index.php/fkip-epro/article/view/4847 9 November 2018.

Tim Penyusun Kamus Besar Bahasa Indonesia. (2018). Kamus Besar Bahasa Indonesia. https://kbbi.kemdikbud.go.id/.

Tobing, R. L. (2012). Tipe Verba Bahasa Prancis dan Perwujudannya Pada Klausa. Litera, Vol. 11 (1): 47 - 59. http://dx.doi.org/10.21831/ltr.v11i1.1146.

Wahida, B. (2017). Kamus Bahasa Arab sebagai Sumber Belajar (Kajian terhadap Penggunaan Kamus Cetak dan Kamus Digital). At-Turas, Vol. 11 (1): 58 - 71. http://jurnaliainpontianak.or.id/index.php/atturats. Diunduh pada 7 November 2018.

Yeka, M. (2016). Analisis Struktur Kamus Umum Monolingual Bahasa Indonesia. E-Journal Bahasa dan Sastra Indonesia-S1 UNY Vol. 5 (1). http://journal.student.uny.ac.id/ojs/index.php/bsi/article/view/1525/2818. Diunduh pada 7 November 2018.

Yusuf, M. (2014). Metode Penelitian Kuantitatif, Kualitatif, dan Penelitian Gabungan. Jakarta: Kencana. 